\title{
Effect of NiW Modified HZSM-5 and HY Zeolites on Hydrocracking Conversion of Crude Palm Oil to Liquid Hydrocarbons
}

\author{
MALIWAN SUBSADSANA and CHALERM RUANGVIRIYACHAI* \\ Materials Chemistry Research Center, Department of Chemistry and Center of \\ Excellence for Innovation in Chemistry (PERCH-CIC), Faculty of Science, \\ Khon Kaen University, Khon Kaen 40002, Thailand. \\ ${ }^{*}$ Corresponding author E-mail: chal_ru@kku.ac.th \\ http://dx.doi.org/10.13005/ojc/320208
}

(Received: March 10, 2016; Accepted: April 22, 2016)

\begin{abstract}
The catalytic conversion of crude palm oil over HZSM- 5 and HY zeolites modified with NiW as catalysts in the hydrocracking process was investigated. These zeolites supported by NiW catalysts were prepared employing the impregnation technique. NiW was added to the zeolites in order to induce bi-functional properties (both acid and metal sites) in the catalysts. Subsequently, the catalysts were characterized by X-ray diffraction spectrometry (XRD), scanning electron microscope (SEM), transmission electron microscope (TEM), ammonia temperature programmed desorption $\left(\mathrm{NH}_{3}-\mathrm{TPD}\right)$ and nitrogen adsorption-desorption isotherms analysis. The catalytic activity of prepared catalysts was evaluated through the conversion of crude palm oil to biofuels. These results indicate that the incorporation of NiW over HZSM-5 and HY zeolites improves the conversion efficiency and enhances the yield of biofuel (gasoline, kerosene, and diesel), possibly due to NiW promote of hydrogenation and dehydrogenation reaction.
\end{abstract}

Keywords: NiW-HZSM-5 zeolite, NiW-HY zeolite, Hydrocracking, Crude palm oil.

\section{INTRODUCTION}

Among all of the vegetable oils, palm oil is one of the vegetable oil that has the greatest possibility to be used in biofuel production since it is one of the most produced vegetable oil in the world. Several researches have been studied in order to efficiently convert this vegetable oil into biofuels such as gasoline and diesel fractions by hydrocracking process $^{1,2}$. Generally, this process involves the utilization of commercially available catalysts and is operated at temperature above $450^{\circ} \mathrm{C}$. Hence, the development of new catalysts, with higher activity under lower temperature conditions, is needed to improve the product yield of palm oil conversion ${ }^{3,4}$.

Zeolite has been widely used as a suitable acidity component in the hydrocracking process due to its appropriate pore structure, thermal stability, and acidity $^{5,6}$. It has been reported that the use of strongly 
acidic catalysts such as $\mathrm{H}$-zeolite can overcome the chemical inertness of the starting alkanes by performing the process at high temperatures ${ }^{7,8}$. Various types of zeolite catalysts were reported in catalytic cracking for the production of biofuels from vegetable oil. They possess a great potential as solid acid cracking catalyst due to its structure, acidity and high selectivity for the production of biofuels from vegetable oils ${ }^{9,11}$. Their catalytic activity involves both hydrogenation and non-hydrogenation processes. The first is a conversion of the triglyceride content in vegetable oil into biofuels, which have lower cyclic hydrocarbon and aromatic contents compared with the conventional ones, while the latter is the dehydration and decarboxylation of biomass oil into gaseous and liquid hydrocarbons, coke, and water $^{12,14}$.

The modification of zeolite with metals has been widely studied since this incorporation can increase the catalytic cracking for the conversion of vegetable oil. Recently, various catalysts such as silica-alumina, USY, $\beta$ and HY-zeolites modified with bimetallic nanoparticles such as NiW, NiMo or CoMo has been reported ${ }^{15-16}$. This combination of metals presents the bi-functional properties, both acid and metal sites, which results in an enhanced efficiency in the hydrocracking conversion of vegetable oils into high quality biofuels ${ }^{17,20}$.

In this work, the incorporation of bimetallic NiW over the HZSM- 5 and HY zeolites was studied. Zeolites were first prepared to the $\mathrm{H}$-form by ion exchange process. The HZSM- 5 and HY zeolites were modified with bimetallic NiW by impregnation method. The catalytic activity of NiW modified HZSM-5 and HY zeolite was evaluated through the hydrocracking conversion of crude palm oil. It can be expected that NiW-HZSM-5 and NiW-HY catalyst could show high activity in crude palm oil hydrocracking process.

\section{MATERIALS AND METHODS}

Nickel nitrate hexahydrate $\left[\mathrm{Ni}\left(\mathrm{NO}_{3}\right)_{2} \cdot 6 \mathrm{H}_{2} \mathrm{O}\right]$ and ammonium metatungstate $\left[\left(\mathrm{NH}_{4}\right)_{6} \mathrm{~W}_{12} \mathrm{O}_{40}\right]$ from Sigma-Aldrich (USA) were utilized as a source of $\mathrm{Ni}$ and $\mathrm{W}$, respectively. Ammonium sulphate $\left[\left(\mathrm{NH}_{4}\right)_{2} \mathrm{SO}_{4}\right]$ was obtained from Labscan(Thailand) for ion exchange. The NaZSM-5 zeolite with $\mathrm{SiO}_{2} / \mathrm{Al}_{2} \mathrm{O}_{3}$ ratio 50 was purchased from the zeolyst international, USA, and ammonium Y zeolite obtained from SigmaAldrich, USA, was used as the reference catalyst. Crude palm oil was supplied by Ubon Ratchathani Palm Oil Co., Ltd., Ubon Ratchathani Province, Thailand, and was further used in the hydrocracking process.

\section{Catalysts}

Firstly, the NaZSM- 5 zeolite was treated in ammonia ion exchange process. An ion exchange process was carried out with a $1 \mathrm{M}\left(\mathrm{NH}_{4}\right)_{2} \mathrm{SO}_{4}$ solution at $90^{\circ} \mathrm{C}$ for $2 \mathrm{~h}$ to give the $\mathrm{H}$-form products (HZSM-5 zeolite). After that, this zeolite was calcined at 550 ${ }^{\circ} \mathrm{C}$ for $3 \mathrm{~h}$ prior to use. In $\mathrm{NH}_{4} \mathrm{Y}$ zeolite, ammonia ion was thermally eliminated at $110^{\circ} \mathrm{C}$ for $4 \mathrm{~h}$ and further calcined at $550^{\circ} \mathrm{C}$ for $3 \mathrm{~h}$. After that, NiW catalysts were deposited on the surface of the zeolite supports by the conventional impregnation technique. A support prepared above was immersed to a mixture solution of $\mathrm{Ni}\left(\mathrm{NO}_{3}\right)_{2} \cdot 6 \mathrm{H}_{2} \mathrm{O}$ and $\left(\mathrm{NH}_{4}\right)_{6} \mathrm{~W}_{12} \mathrm{O}_{40}$ for $1 \mathrm{~h}$. Each catalyst supported contains 8 wt.\% W and 4 wt.\% Ni. After impregnation, the catalyst was dried at $110^{\circ} \mathrm{C}$ for $5 \mathrm{~h}$, and then calcined at $550{ }^{\circ} \mathrm{C}$ for $3 \mathrm{~h}$.

\section{Characterization}

The physicochemical properties of the prepared catalysts were characterized by means of various conventional techniques. X-ray diffraction patterns were obtained using a Shimadzu-6000 diffractometer with $\mathrm{Cu} \mathrm{K} \alpha$ radiation at $40 \mathrm{~mA}$ and $40 \mathrm{kV}$. The step size of 0.02 and a step time of 0.5 $\mathrm{s}$ for the range of 5 to $80^{\circ}$ were employed. The total amount of $\mathrm{Ni}$ and $\mathrm{W}$ in the impregnated catalyst was determined by PANalytical PW-2404 X-ray fluorescence spectroscopy (XRF). The morphologies were examined using JSM-5410LV scanning electron microscope (SEM). Transmission electron microscopy (TEM) micrographs were recorded with a JEOL 2010F electron microscope operating at $200 \mathrm{kV}$. Prior to the observation, the catalysts were dispersed in ethanol solution, stirred in an ultrasonic bath and deposited on a copper grid. The surface area and porous properties of catalysts before and after modification with NiW were studied using nitrogen adsorption-desorption isotherms recorded on a Quantachrome Autosorb Automated Gas Sorption analyzer at $77 \mathrm{~K}$. The catalysts were degassed in vacuum for $3 \mathrm{~h}$ at $300{ }^{\circ} \mathrm{C}$. The surface 
area was calculated by the brunauer-emmett-teller (BET) isothermal equation, based on $\mathrm{p} / \mathrm{p}_{\mathrm{o}}$ data in the range of $0.0-1.0$. The pore volume was obtained from the t-plot method. The acid properties were measured by ammonia temperature programmed desorption (TPD) in a Quantachrome ChemBET 3000 with a thermal conductivity detector (TCD). 80 mg sample was placed in a quartz tubular reactor and pretreated at $600^{\circ} \mathrm{C}$ with a $\mathrm{N}_{2}$ flow of $30 \mathrm{~mL} /$ min for $1 \mathrm{~h}$ and then cooled to $100^{\circ} \mathrm{C}$. Ammonia diluted with $\operatorname{Ar}\left(5 \% \mathrm{v} / \mathrm{v} \mathrm{NH}_{3}\right)$ was then introduced at a flow rate of $30 \mathrm{~mL} / \mathrm{min}$ for $1 \mathrm{~h}$ at $100{ }^{\circ} \mathrm{C}$ and then a He stream was fed in until TCD signal was constant. $\mathrm{NH}_{3}$-TPD was performed with the reactor temperature at a ramp rate of $10^{\circ} \mathrm{C} / \mathrm{min}$ from $100{ }^{\circ} \mathrm{C}$ to $700{ }^{\circ} \mathrm{C}$.

\section{Catalytic hydrocracking}

In order to evaluate the activity of the prepared catalyst, the catalytic conversion of crude palm oil $\left(500 \mathrm{~cm}^{3}\right)$ was performed in batch reactor with a volume of $1 \mathrm{~L}$. $5 \mathrm{~g}$ catalyst was fed into the reactor. The mixture was automatically and continuously stirred at $500 \mathrm{rpm}$. Then, the reactor was heated electrically with a control of a thermocouple. Initially, a reactor was purged with $\mathrm{N}_{2}$ gas for 30 min to completely eliminate $\mathrm{O}_{2}$ gas. Then, the reactor was flown with $\mathrm{H}_{2}$ gas at a flow rate of $500 \mathrm{~cm}^{3} \mathrm{~min}^{-1}$ and 3.0 MPa pressure for 30 minute. Thereafter, the catalytic runs were performed by heating the reactor up to $400{ }^{\circ} \mathrm{C}$ and then hold for $120 \mathrm{~min}$ of reaction time (pressure up to 8.0 MPa). After the complete catalytic reaction, the reactor was stopped and allowed to cool down to the ambient temperature. Furthermore, the liquid product from hydrocracking process was distilled, separated using a distillation funnel at $150-350^{\circ} \mathrm{C}$, and collected with a glass vial.

\section{RESULTS AND DISCUSSION}

The surface topography, crystal structure, chemical component, surface area, and pore volume of NiW-HZSM-5 and NiW-HY catalysts were characterized by XRD, SEM, TEM, $\mathrm{NH}_{3}-$ TPD and $\mathrm{N}_{2}$ adsorption-desorption measurement, in comparison with the corresponding HZSM-5 and HY zeolites.

XRD patterns of HZSM-5, HY, and impregnated catalysts are shown in Fig. 1. The results showed the similar characteristic peaks, indicating that the impregnation of HZSM- 5 and $\mathrm{HY}$ zeolites with NiW did not affect the crystallinity of zeolites. Additionally, the disappearance of $\mathrm{Ni}$ and $\mathrm{W}$ peaks was observed, possibly due to the dispersion of metals over the external surface of HZSM-5 and HY zeolites.

As shown in Fig. 2, SEM images illustrated that HZSM-5 and HY zeolites are easily aggregated to form nanoparticles. Therefore, the modification of zeolites with NiW did not change the physical morphologies of HZSM-5 and HY zeolites. Fig. 3 illustrates TEM images of the catalysts before and after the incorporation with NiW. TEM images show the presence of relatively large NiW over the external surface of HZSM-5 zeolite crystals, as can be seen in Fig. 3b. In contrast, the NiW located mainly within the HY zeolite channels rather than on the external surface of the zeolite nanocrystals, as shown in Fig. $3 d$. Therefore, HZSM-5 zeolite presents a much higher dispersion of metal than HY zeolite.
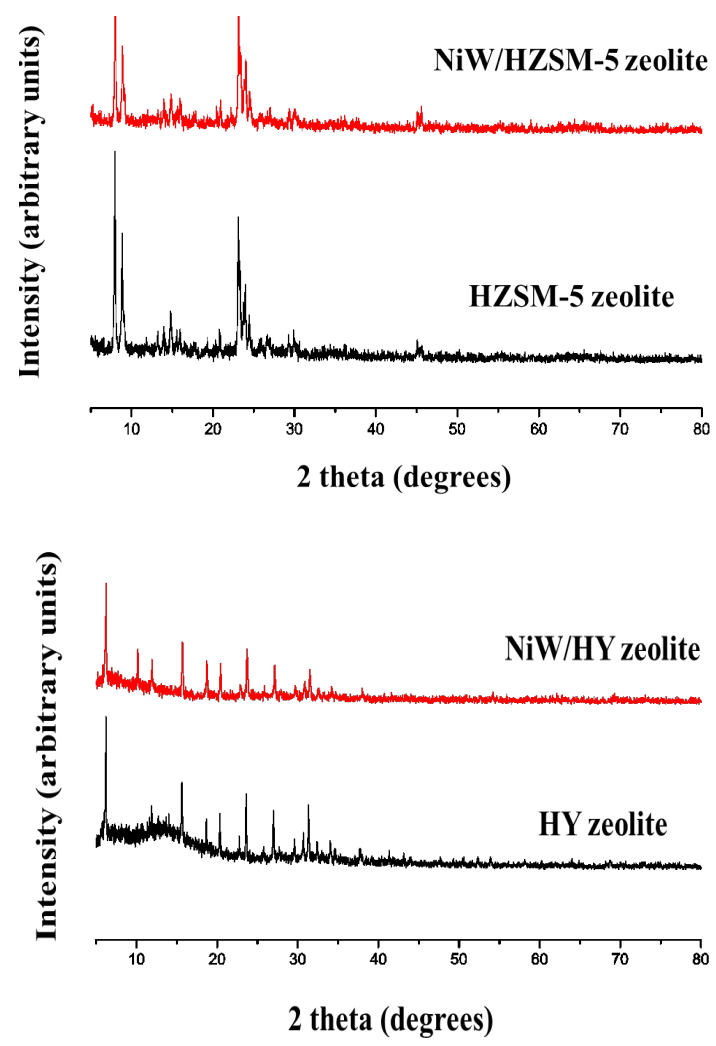

Fig. 1: XRD patterns of HZSM-5 and HY zeolites before and after modification with NiW 
The textural properties of the catalysts were determined using the $\mathrm{N}_{2}$ adsorption isotherms and the surface area was calculated by the BET method. Table 1 shows the difference in textural properties of catalysts before and after modification with NiW. When adding NiW into the zeolite, it was found that a more pronounced decrease in the micropore volume takes place, resulting from a partial blockage of the zeolite channels by metal particles. The results are in agreement with the reduction of the BET surface area for the NiW modified zeolites.
Table 2 shows the effect of the catalysts with different type zeolite and doping metals on the biofuels yield of the crude palm oil reaction. It was found that the hydrocracking reaction products increased significantly when $\mathrm{Ni}$ and $\mathrm{W}$ were incorporated into the catalyst, possibly due to their role as promoters in hydrogenation and dehydrogenation and aromatic hydrocarbons reaction. Indeed, most of metals are dispersed on the outer surface and the metallic diffusion and its sintering throughout the framework affect the

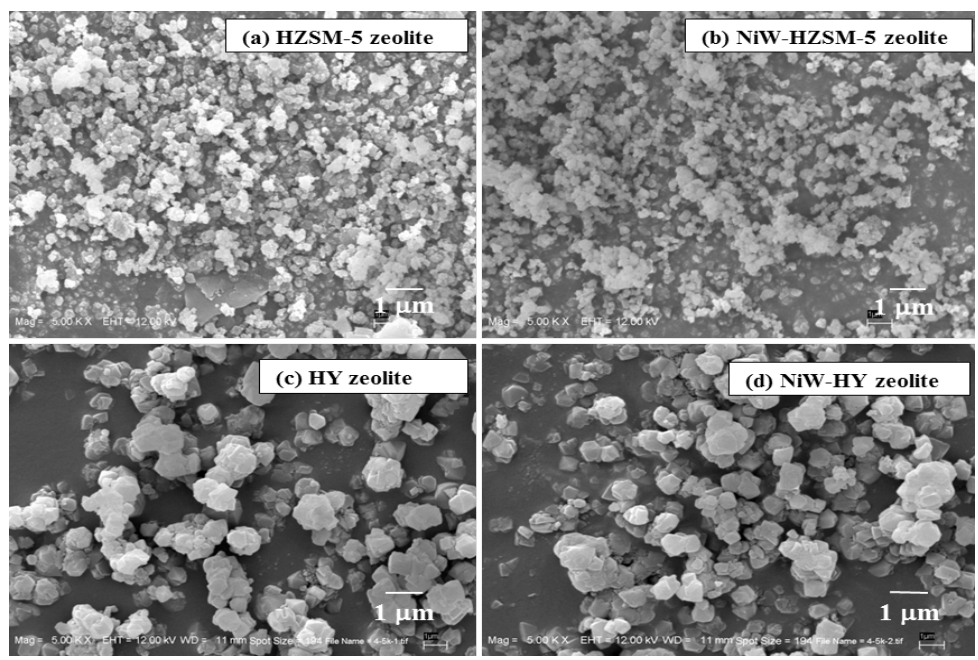

Fig.2: SEM images of HZSM-5 and HY zeolites before and after modification with NiW: (a) HZSM-5 zeolite, (b) NiW-HZSM-5 zeolite, (c) HY zeolite and (d) NiW-HY zeolite, respectively

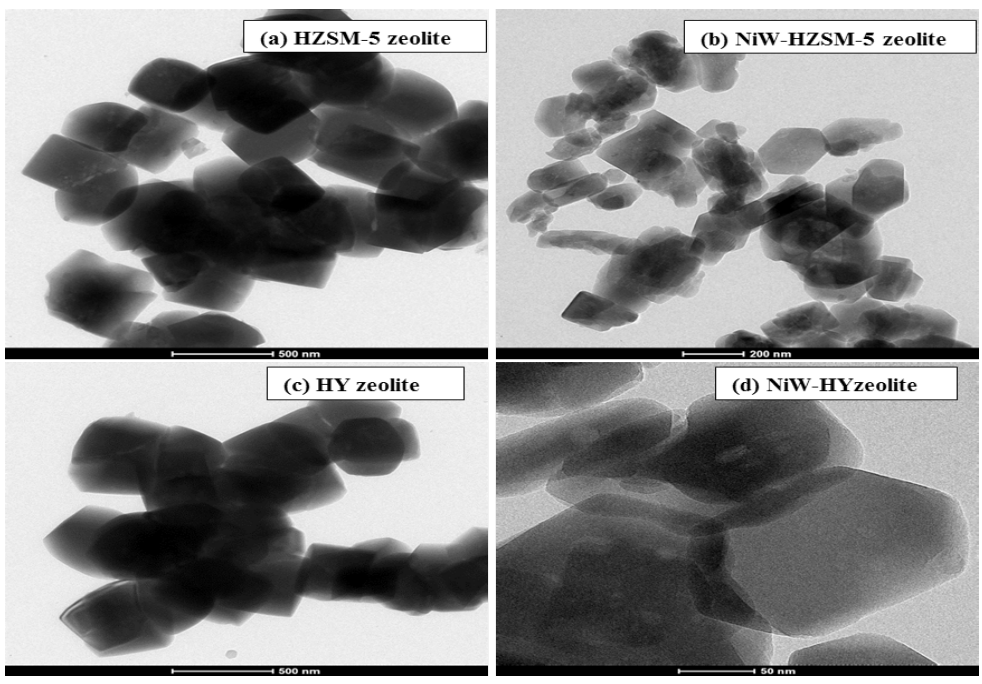

Fig. 3: TEM images of HZSM-5 and HY zeolites before and after modification with NiW: (a) HZSM-5 zeolite, (b) NiW-HZSM-5 zeolite, (c) HY zeolite and (d) NiW-HY zeolite, respectively 
Table 1: Metal content, BET surface area and pore volume of catalyst before and after modification with NiW

\begin{tabular}{|c|c|c|c|c|c|c|}
\hline \multirow{3}{*}{ Catalyst } & \multirow{2}{*}{\multicolumn{2}{|c|}{$\begin{array}{l}\text { Metal } \\
\text { content } \\
\text { (wt\%) }\end{array}$}} & \multicolumn{2}{|c|}{ Before modification } & \multicolumn{2}{|c|}{ After modification } \\
\hline & & & \multirow{2}{*}{$\begin{array}{c}\text { Surface area } \\
\left(\mathrm{m}^{2} \mathrm{~g}^{-1}\right)\end{array}$} & \multirow{2}{*}{$\begin{array}{l}\text { Pore volume } \\
\qquad\left(\mathrm{cm}^{3} \mathrm{~g}^{-1}\right)\end{array}$} & \multirow{2}{*}{$\begin{array}{l}\text { Surface area } \\
\qquad\left(\mathrm{m}^{2} \mathbf{g}^{-1}\right)\end{array}$} & \multirow{2}{*}{$\begin{array}{l}\text { Pore volume } \\
\qquad\left(\mathrm{cm}^{3} \mathbf{g}^{-1}\right)\end{array}$} \\
\hline & $\mathrm{Ni}$ & w & & & & \\
\hline HZSM-5 & 3.11 & 7.33 & 345.9 & 0.305 & 253.4 & 0.196 \\
\hline HY & 3.16 & 7.42 & 249.8 & 0.212 & 221.7 & 0.119 \\
\hline
\end{tabular}

Table 2: The effect of the catalysts with different type zeolite doping metals on biofuels of crude palm oil reaction $(n=3)$

\begin{tabular}{|c|c|c|c|c|c|}
\hline \multirow[t]{2}{*}{ Catalyst A } & \multirow[t]{2}{*}{$\begin{array}{c}\text { Acid amount } \\
\left(10^{-4} \mathrm{~mol} / \mathrm{g}\right)\end{array}$} & \multirow[t]{2}{*}{ Conversion (\%) } & \multicolumn{3}{|c|}{$\begin{array}{c}\text { Yield } \\
(\%)\end{array}$} \\
\hline & & & $\begin{array}{c}\text { Gasoline } \\
\left(150-200^{\circ} \mathrm{C}\right)\end{array}$ & $\begin{array}{c}\text { Kerosene } \\
\left(250-300^{\circ} \mathrm{C}\right)\end{array}$ & $\begin{array}{l}\text { Diesel } \\
350^{\circ} \mathrm{C}\end{array}$ \\
\hline HZSM-5 & 0.42 & 37.20 & $6.30 \pm 0.2$ & $14.10 \pm 0.3$ & $16.80 \pm 0.5$ \\
\hline $\mathrm{HY}$ & 0.76 & 38.57 & $8.65 \pm 0.8$ & $13.30 \pm 0.2$ & $16.62 \pm 0.2$ \\
\hline NiW-HZSM-5 & $\begin{array}{ll}-5 & 0.33\end{array}$ & 48.18 & $10.40 \pm 0.1$ & $19.56 \pm 0.4$ & $18.22 \pm 0.6$ \\
\hline NiW-HY & 0.63 & 50.38 & $13.88 \pm 0.2$ & $18.20 \pm 0.5$ & $18.30 \pm 0.3$ \\
\hline
\end{tabular}

catalyst. It can be seen that the gasoline yield over the NiW-HY zeolite catalyst was higher, compared to that over the NiW-HZSM- 5 zeolite catalyst, while the kerosene yield over the NiW-HZSM-5 zeolite catalyst was higher, compared to that over the NiWHY zeolite catalyst. The results indicated that the catalysts doped with NiW had better hydrocracking performance, compared to the catalyst without metal modification. It can also be observed that the NiW-HY zeolite catalyst had higher acid amount, when compared to the NiW-HZSM-5 zeolite. The results imply that catalyst with higher acid amount shows better activity. Moreover, the NiW-HZSM-5 and NiW-HY cataysts exhibit enhanced production of liquid biofuels with a significant increase in gasoline, kerosene and diesel fractions.

\section{CONCLUSIONS}

The conversion of crude palm oil into liquid hydrocarbons over bimetallic NiW -HZSM-5 and NiW-HY catalysts was studied. NiW was deposited on the surface of zeolites by impregnation method. The incorporation of NiW into the HZSM-5 and HY zeolites causes an important change in textural properties, which has an influence on the catalytic conversion. It was found that the conversion efficiency over NiW- HZSM-5 and NiW-HY was higher than that of HZSM-5 and NiW-HY catalysts, indicating that an incorporation of NiW in zeolites improves their catalytic activity. Hence, bi-functional materials, based on W and Ni loaded over crystalline HZSM-5 and HY zeolites, can be considered interesting catalysts for the conversion of crude palm oil into biofuels.

\section{ACKNOWLEDGEMENTS}

This work is supported by Nakhon Ratchasima Rajabhat University for financial support and Materials Chemistry Research Center, Department of Chemistry Faculty of Science, Khon Kaen University, Thailand, for research facility and grant. In addition, National Research University project of Thailand, the Biofuel Cluster of Khon Kaen University, Thailand, are also gratefully acknowledged for the chemicals. 


\section{REFERENCES}

1. N. Taufiqurrahmi, A.R. Mohamed, S. Bhatia Chem. Eng. J., 2010; 163, 413-421.

2. Y.S. Ooi, A.R. Zakaria, R. Mohamed, S. Bhatia. Appl. Catal. A: Gen.,2004; 274, 15-23.

3. Y. Zhao, X. Lin, D. Li. Chem. Eng. Technol., 2015; 38, 297-303.

4. N. Chang, Z. Gu, Z. Wang, Z. Liu, X. Hou, J. Wang. J. Porous Mater.,2011; 18, 589-596.

5. Q. Jian, Z. Tianbo, X. Xin, L. Fengyan, S. Guida. China. Pet. Process. Pe.,2010; 12, 17-22.

6. W. Guang, W. Wei, W. Xin, Z. Wang, W. Wenjing, L. Cheng. Microporous Mesoporous Mater., 2013; 180,187-195.

7. L. Hansheng, H. Shichao, M. Ke, W. Qin, J. Qingze, S. Kening. Appl. Catal. A: Gen., 2013; 450, 152-159.

8. Y. Sang, H. Liu, S. He, H. Li, Q. Jiao, Q. Wu, K. Sun. J Energy Chem., 2013; 22,769-777.

9. J. Qi, T. Zhao, F. Li, G. Sun, X. Xu, C. Miao, H. Wang, X. Zhang. J. Porous Mater.,2010; 17,177-184.

10. D. Kubièka, L. Kaluža. Appl. Catal. A: Gen., 2010; 372, 199-208.
11. D. Han, N. Sun, J. Liu, C. Li, H. Shan, C. Yang J Energy Chem., 2014;23, 519-526.

12. D.P. Serrano, J. Aguado, J.M. Rodriguez, A. Peral. J. Anal. Appl. Pyrolysis., 2007; 79, 456464.

13. P. Liu, Z. Zhang, M. Jia, X. Gao, J. Yu. Chin. J. Catal., 2015; 36, 806-812.

14. L. Zhao, J. Gao, C. Xu, B. Shen. Fuel Process. Technol.,2011; 92,414-420.

15. J.A. Botas, D.P. Serrano, A. García, R. Ramos. Appl. Catal. B: Environ., 2014; 145, 205215.

16. J.A. Botas, D.P. Serrano, A. García, J.de. Vicente, R. Ramos. Catal.Today.,2012; 195, 59-70.

17. D. Han, N. Sun, J. Liu, C. Li, H. Shan, C. Yang. J. Eng.Chem., 2014; 23, 519-526.

18. S. Bendezú, R. Cid, J.L.G. Fierro, A. LópezAgudo. Appl. Catal. A: Gen., 2000; 197, 47-60.

19. A. Ishihara, T. Itoh, H. Nasu, T. Hashimoto, T. Doi. Fuel Process. Technol.,2013; 116, 222227.

20. M.A. Ali, T. Tatsumi, T. Masuda. Appl. Catal. A: Gen., 2002; 233, 77-90. 